\title{
PUER SACER: LA VIOLENCIA ABSOLUTA ${ }^{1}$
}

\author{
Napoleón Saltos Galarza²
}

RESUMEN: La identidad de la humanidad como comunidad de seres humanos se extiende hasta el límite en que reconocemos al otro como tal, como ser humano. La frontera ha variado en la historia. La tesis central del texto es que en la modernidad líquida, el borde del nuevo sujeto universal es el puer sacer; ya no sirven las murallas íntimas de la familia, de la escuela, de la iglesia, para proteger el cuerpo de las nuevas víctimas. Las estadísticas y los casos muestran que esta violencia está ligada al biopoder, como un proceso estructural. Millones de niños y niñas mueren en silencio impunemente o sobreviven en la zoé. La violencia infantil en los mass media y en las redes sociales es parte del formateo permanente de los individuos para bloquear las posibilidades de una conciencia crítica y el reconocimiento de que en la edad primera se define las bases de la liberación y de la identidad. Las respuestas jurídicas globales y locales, proclaman el derecho superior del niño a la protección del Estado; pero hay distancia con las normas de aplicación y con las políticas concretas. ¿Hay salida? Se plantea que el problema es político. La defensa de los derechos y la vida de las niñas y niñas entra en una dimensión civilizatoria, post-capitalista y post-patriarcalista. Presenta alternativas en torno a la ética de la eleidad, las pedagogías liberadoras y la parrhesía.

Palavras Clave: Niños y niñas. Puer sacer. Violencia infantil. Ecuador. Parrhesía.

\section{PUER SACER: A VIOLÊNCIA ABSOLUTA}

RESUMO: A identidade da humanidade como comunidade de seres humanos estende-se até o limite no qual reconhecemos ao outro como tal, como ser humano. Essa fronteira tem variado no percurso histórico. A tese central do texto é que, na modernidade líquida, os contornos do novo sujeito universal é o puer sacer; já não servem as muralhas íntimas da família, da escola, da igreja, para proteger o corpo das novas vítimas. As estatísticas e os casos mostram que essa violência está ligada ao biopoder, como um processo estrutural. Milhões de crianças morrem em silêncio impunemente ou sobrevivem na zoé. A violência infantil dos mass media e nas redes sociais é parte do formato permanente para bloquear nos indivíduos as possibilidades de uma consciência crítica e o reconhecimento de que nos primeiros anos de vida definem-se as

\footnotetext{
${ }^{1}$ Agradezco las observaciones y aportes de Beatriz Stolowicz, Gayne Villagómez y Patricia Calero.

${ }^{2}$ Doctor en Estudios Políticos y Constitucionales. Profesor de la Universidad Central del Ecuador. Director de la Revista Ciencias Sociales de la Facultad de Ciencias Sociales y Humanas de la Universidad Central del Ecuador. Endereço eletrônico: wnsaltosg@yahoo.es.
} 
bases da liberação e da identidade. As respostas jurídicas globais e locais proclamam o direito superior das crianças à proteção do Estado; mas existe uma distância entre as normas e sua aplicação, assim como com as suas políticas concretas. Há saída? Argumenta-se que o problema é político. A defesa dos direitos e da vida das crianças entra numa dimensão civilizatória, pós-capitalista e pós-patriarcal. Apresentam-se alternativas em torno da ética da eleidad, as pedagogias libertadoras e a paresia.

Palavras-chave: Crianças. Puer sacer. Violência infantil. Equador. Paresia

\section{PUER SACER: ABSOLUTE VIOLENCE}

ABSTRACT: The identity of humanity as a community of human persons extends to the limit where we recognize the other as such, as a human person. The border has varied in history. The central thesis of the text is that in liquid modernity, the edge of the new universal subject is puer sacer; the intimate walls of the family, the school, the church, no longer serve to protect the body of the new victims. Statistics and cases show that this violence is linked to biopower, as a structural process. Millions of children die in silence with impunity or survive in the zoé. Child violence in the mass media and in social networks is part of the permanent format of individuals to block the possibilities of a critical conscience and the recognition that in the first age the bases of liberation and identity are defined. The global and local legal responses proclaim the superior right of the child to the protection of the State; but there is distance with the rules of application and with the concrete policies. Is there an exit? It is argued that the problem is political. The defense of the rights and lives of girls and boys enters into a civilizing, post-capitalist and post-patriarchal dimension. Presents alternatives around the ethics of the otherness, liberating pedagogies and parrhesia.

Keywords: Children. Puer sacer. Child violence. Ecuador. Parrhesia

He cerrado mi balcón

Porque no quiero oír el llanto

Pero por detrás de los grises muros

No se oye otra cosa que el llanto.

Hay muy pocos ángeles que canten,

Hay muy pocos perros que ladren, Mis violines caben en la palma de mi mano.

Pero el llanto es un perro inmenso, El llanto es un ángel inmenso, Las lágrimas amordazan al viento, No se oye otra cosa que el llanto.

Federico García Lorca

-Llámalo Voldemort, Harry. Utiliza siempre el nombre correcto de las cosas. El miedo a un nombre aumenta el miedo a la cosa que se nombra. (Rowling 1999, 207)

\section{El tiroteo en la escuela}


En Estados Unidos periódicamente se presentan tiroteos en los centros educativos. El miedo y nuevas formas de violencia armada, apoderados de la escuela, la escuela profanada por la violencia. La respuesta del Estado, el operativo de seguridad. Doble cerco, del agresor y del Estado. Los agresores en la mayor parte son exalumnos. Y en medio, el espectáculo. La disputa por el "monopolio de la violencia física" no se dirige contra el Estado, sino que devora el cuerpo social.

\section{El otro}

La identidad de la humanidad como comunidad de seres humanos se extiende hasta el límite en que reconocemos al otro como tal, como ser humano. Una frontera que se mueve en el tiempo y la geografía, construida socialmente.

En el principio era la comuna, todos éramos hermanos y hermanas. Una identidad compartida, indiferenciada, como en la fase del espejo, el niño/niña todavía no se extraña del cuerpo de la madre y del medio, aún no separa su propio cuerpo, reacciona con todo su ser naciente. En la comunidad originaria cada ser es necesario en la felicidad y ante la amenaza.

El pecado original fue negarle el alma al otro, a ella-él. El imperio del Uno. Todo empezó antes del paraíso. Lilith ha vagado sola, oculta; ahora empieza a volver por la puerta de un tiempo mítico.

En la historia de Occidente, la ruptura se produjo cuando se proclamó el dios solitario y la instauración del patriarcalismo. "El derrocamiento de esas diosas poderosas y su sustitución por un dios dominante ocurre en la mayoría de las sociedades del Próximo Oriente tras la consolidación de una monarquía fuerte e imperialista. Gradualmente, la función de controlar la fertilidad, hasta entonces en poder de las diosas, se simboliza con el acto de unión, simbólica o real, del dios o el rey divino con la diosa o su sacerdotisa. Por último, se separa la sexualidad (erotismo) y la procreación con la aparición de una diosa distinta para cada función, y la diosa madre se transforma en la esposa o consorte del principal dios masculino. (...) Esta devaluación simbólica de las mujeres en relación con lo divino pasa a ser una de las metáforas de base de la civilización occidental. La filosofía aristotélica proporcionará la otra metáfora de base al dar por hecho que las mujeres son seres humanos incompletos y defectuosos, de un orden totalmente distinto a los hombres." (Lerner 1990) 
En cada tiempo histórico y en cada geografía aparece el Otro negado absoluto en el borde de la humanidad. La historia de la negación no se reduce a Occidente. El patriarcalismo y las negaciones superpuestas del Otro - sexo, género, clases, etnias, razas, edades, nación, religión - tienen sus diferentes formas civilizatorias también en Oriente. Los procesos son complejos. En las sociedades recolectoras, por ejemplo, no pasa por la relación directa con la propiedad privada, la constitución de clases y del Estado, sino que se presenta como un proceso más autónomo.

La fuente común es la ruptura entre el alma, el espíritu y el cuerpo, para convertirlo a éste en la fuente del mal y en la base de la apropiación material. Tiene razón Gerda Lerner (1990), cuando plantea que la explotación y dominación sexual de las mujeres está en la génesis de la constitución de la propiedad privada y de las clases sociales. Sobre esta raíz común, hay que reconstituir cada historia, superar las visiones esencialistas (biologistas o psicoanalíticas) que deshistorizan, eternizan el orden sexual, para reconocer los caminos concretos de la dominación en cada geografía, en cada época, a fin de abrir las posibilidades de una acción colectiva de resistencia y liberación. (Bourdieu 2000, 8)

En la Abya-Yala, la ruptura moderna empezó cuando el primer conquistador preguntó: ¿los indios tienen alma? No importaba la respuesta. Apenas el debate precursor de Bartolomé De las Casas: ante la acusación de Juan De Sepúlveda de que eran bárbaros, necesitaban la tutela de los cristianos y podían ser sometidos a la fuerza con guerras justas de conquista, defendió que en diversos aspectos los indios estaban más adelantados que muchos cristianos y eran capaces de autogobernarse.

“Con perfecto derecho los españoles imperan sobre estos bárbaros del Nuevo Mundo e islas adyacentes, los cuales en prudencia, ingenio, virtud y humanidad son tan inferiores a los españoles como niños a los adultos y las mujeres a los varones, o los negros a los blancos, habiendo entre ellos tanta diferencia como la que va de gentes fieras y crueles a gentes clementísimas.” (De Sepúlveda 1550) La modernidad occidental empezó con la fractura de la raza, bajo el dominio de la cruz y la espada. Los indios tuvieron que acudir a las rebeliones para mostrar su presencia, aunque por debajo crearon, como resistencia silenciosa, encubierta, el ethos barroco.

Y desde allí, arrebataron doblemente el alma a las mujeres y a los niños/niñas. Las mujeres indias fueron fuente de uso y abuso, y las mestizas fueron relegadas a ser y no ser, estar y no estar. Hasta ahora han desaparecido de la historia, aunque empiezan a volver, como 
Lilith, por obra de las mujeres antes del paraíso y del infierno. Los niños apenas eran el número para reponer la fuerza de trabajo arrebatada por el genocidio conquistador.

“La globalización en curso es, en primer término, la culminación de un proceso que comenzó con la constitución de América y la del capitalismo colonial/moderno y eurocentrado como un nuevo patrón de poder mundial. Uno de los ejes fundamentales de ese patrón de poder es la clasificación social de la población mundial sobre la idea de raza, una construcción mental que expresa la experiencia básica de la dominación colonial y que desde entonces permea las dimensiones más importantes del poder mundial, incluyendo su racionalidad específica, el eurocentrismo. Dicho eje tiene, pues, origen y carácter colonial, pero ha probado ser más duradero y estable que el colonialismo en cuya matriz fue establecido." (Quijano 2000, 201)

En la modernidad capitalista consolidada, Engels, y luego Marx, vieron en la clase obrera el otro negado: "La situación de la clase obrera es el suelo y punto de partida fáctico de todos los movimientos sociales actuales, porque es la más alta, la más visible cumbre de nuestra constitutiva miseria”. (Engels 1845). El sistema capitalista se basa en la expropiación del producto del trabajo y de la vida del obrero y su familia. Desde allí, el marxismo pudo proclamar al proletariado como el sepulturero del capitalismo. Liberar "la más alta cumbre de nuestra miseria", era el "punto de partida" de la liberación de toda forma de miseria, la reconstrucción de la humanidad como comunidad de hermanos, la utopía del comunismo.

"Descubre así a la víctima del sistema que debe ser afirmada en su dignidad y negada en su negación, según la dialéctica de lo positivo y lo negativo. Siendo la víctima universal o del sistema como tal, su liberación significa la "disolución” total del sistema: "Allí donde el proletariado proclama la disolución del orden universal anterior, no hace sino pregonar el secreto de su propia existencia, ya que él es de hecho la disolución de este orden universal." (Marx, Introducción a la crítica de la Filosofía del Derecho de Hegel 1956 (1844)) (Dussel $1998,316)$

Hay varios bordes, grietas del sistema, en donde se construyen los sujetos que pueden proclamar la "disolución del orden universal" en su propia negación; superposición, convergencia de las víctimas universales: clase, género, raza, etnia, nacionalidad, edad, desparramadas en cuerpos diferenciados o a menudo conjuntadas en un mismo cuerpo extremo. "El tema propiamente ético no se inicia tanto en la positividad de la vida humana, sino en su negatividad, en el no poder vivir, cuestión que necesita sin embargo el horizonte positivo.” (Dussel 1998, 317-318) 
En el Viejo Continente, el tiempo final empezó cuando el Fürher ordenó los asesinatos de los judíos, de los gitanos, de los homosexuales, de los enfermos mentales. “... la experiencia que marcará por mucho tiempo a la humanidad europea: la exterminación acometida por los nazis. Que la obra mortal — que de hecho oculta la propia muerte, su dignidad, en la aniquilación - haya sido realizada en nombre de la comunidad -ya sea la de un pueblo o de una raza autoconstituida, ya sea la de una humanidad autotrabajada- es lo que puso término a toda posibilidad de reposar sobre cualquier dato del ser común (sangre, sustancia, filiación, esencia, origen, naturaleza, consagración, elección, identidad orgánica o mística). A decir verdad, incluso es lo que puso término a la posibilidad de pensar un ser común bajo cualquier modelo de un «ser» en general. El estar-en-común, allende el ser pensado como identidad, como estado o como sujeto; el estar-en-común que afecta al ser mismo en lo más profundo de su textura ontológica. " (Nancy 2000, 8)

Ya no fue posible reconstruir la totalidad, el sentido de la humanidad, la fraternidad universal, ser-con-nosotros. Empezó a reinar la soledad. El dios único, sin la diosa; el inti, el sol, sin la luna, sin la quilla; la cantidad, el valor de cambio, sin el valor de uso, sin la cualidad; el individuo como átomo perdido en el espacio y en el tiempo, sin comunidad.

El espacio emblemático fue el campo de concentración. Giorgio Agamben lo toma como la metáfora del territorio que habita "la nuda vida, es decir la vida a quien cualquiera puede dar muerte pero que es a la vez insacrificable del homo saccer", expresión de la nueva forma de la política moderna como biopolítica, ya no sólo como "la inclusión de la zöé en la polis, en sí misma antiquísima, ni el simple hecho de que la vida como tal se convierta en objeto eminente de los cálculos y previsiones del poder estatal: lo decisivo es, más bien, el hecho de que, en paralelo al proceso en virtud del cual la excepción se convierte en la regla, el espacio de la nuda vida que estaba originariamente al margen del orden jurídico, va coincidiendo de manera progresiva con el espacio político, de forma que exclusión e inclusión, externo e interno, bíos y zöé, derecho y hecho, entran en una zona de irreductible indiferenciación." (Agamben 1998, 18 y 19)

La antigua frontera entre público y privado se disuelve, el territorio se amuralla y se seguriza, la vida pasa de la soberanía y la disciplina al control. La Mátrix busca no dejar un afuera, todo se diluye en el control; y sin embargo en su propia constitución la inclusión totalitaria se convierte en exclusión absoluta, la vida queda en el borde, ya no sólo como vida humana, sino como bíos, el retorno a la relación originaria del homo sacer con la naturaleza. Y allí se abren nuevas grietas, el sitio del dominio es también el sitio de la emancipación. La 
antinomia de la vida como objeto de la política, como su negación, y la posibilidad de su liberación, abre la posibilidad de un sentido alternativo en el extremo, en el sujeto negado. "Según el testimonio de Antelme, lo que los campos de concentración habían enseñado de verdad a sus moradores era precisamente que "el poner en entredicho la cualidad de hombre provoca una reacción cuasi biológica de pertenencia a la especie humana." (Agamben 1998, 20)

En la "modernidad líquida" (Bauman 2004), el borde del nuevo sujeto universal es el puer sacer; ya no sirven ni siquiera las murallas íntimas de la familia, de la escuela, de la iglesia, para proteger el cuerpo de las nuevas víctimas; las estadísticas dicen que en las violaciones el 67\%, 2 de cada 3 agresores son personajes allegados, tíos, primos, maestros, curas, profesores, padres, abuelos, entrenadores, vecinos. Ya no los carceleros, sino los protectores. La mercantilización del cuerpo y su objetalización es parte de la expansión del capital que va rompiendo las fronteras de la justicia, de la ética, de los derechos y de los consensos sociales.

Esta disolución se presenta en su forma global en la paradoja de la expansión del mundo virtual: la posibilidad del acceso directo a la información para abrir cauces de comunicación universal se transforma, en manos del capital, en la reproducción permanente de la dominación desde adentro, sobre todo dirigido a las nuevas generaciones.

Para los niños y niñas el mal está edulcorado, la magia Disney no tiene misterio: "un encantamiento light cuyo objetivo central es apartar a la infancia y a la adolescencia de toda experiencia emancipadora.” (Bustelo 2007, 59) Un mundo maravilloso carente de fantasía. El choque entre el mundo consumido por las niñas y niños en los medios, en los juegos virtuales, en el reciclaje de los cuentos y las historietas, y el mundo violento que los devora, crea un espacio de vulnerabilidad que es copado por diversas formas de biopoder. La distancia entre estrategias de construcción de las subjetividades-identidades y las estrategias se disuelve.

La familia, la escuela y la iglesia, antiguos refugios del puer sacer, ahora están asediados por el mundo del consumo, subordinados al funcionamiento de la industria cultural de masas, orientado a crear consumidores subordinados, pasivos. "Estamos entonces entendiéndonos con una familia desorganizada en su lógica interna, oprimida desde la economía y colonizada por los medios de comunicación masiva y la industria cultural." (Bustelo 2007, 64)

\section{Los números}


Las estadísticas son abrumadoras. 6 de cada 10 mujeres entre 15 y 64 años han sido víctimas de violencia de género en algún momento de su vida. El 25\% han sufrido violencia sexual, de las cuales el 25,7\% fueron agredidas antes de los 18 años. (Comisión de Transición e INEC 2011)

Según el Informe Alternativo de la Coalición Nacional de Mujeres del Ecuador al CDN 2016, el Ecuador ocupa el tercer puesto en América Latina con mayor tasa de embarazo adolescente, en varios casos, fruto de violación; las niñas y adolescentes menores de catorce años son las principales víctimas de la violencia sexual. (Coalición Nacional de Mujeres del Ecuador 2016)

En el 2013, se registraron 634 denuncias de violencia sexual contra niñas y adolescentes, de las cuales el $85 \%$ se relacionaba con violaciones. Apenas el $6 \%$ fueron procesadas. En el 2014, se registraron 271 denuncias de delitos sexuales en instituciones educativas. "En todos los casos mencionados en este informe, ninguna de las instituciones escolares públicas ni privadas donde se perpetraron los hechos han sido sancionadas administrativa ni judicialmente, aun cuando en los mismos la mala fe y el encubrimiento han sido evidentes; así como tampoco han sido condenados los violadores, denotando una clara tolerancia por parte del Estado ecuatoriano frente a este tipo de delitos." (Coalición Nacional de Mujeres del Ecuador 2016)

El $82,5 \%$ de las madres cree que las niñas indígenas de la Sierra Central no pueden evitar la violencia sexual; y el 54,9\% cree que los niños tampoco lo pueden. "Los actores de los casos de violencia sexual extrema (manoseo, violación) siguen siendo la familia o los amigos, en su gran mayoría." (Viteri y otros 2017, 113)

La escuela ha sido profanada. En el país, 3 de cada 5 niños han sufrido algún tipo de violencia en la escuela: $22,92 \%$ delitos sexuales; $24,50 \%$ lesiones; $52,58 \%$ maltrato sicológico. En referencia a los delitos sexuales, de acuerdo a las estadísticas del ingreso de víctimas al Sistema de Protección a Víctimas por tipo de delito en el ámbito educativo en el período 2013-septiembre 2016, 55\% acoso sexual, 23\% abuso sexual, 14\% violación, 9\% atentado al pudor. El $86 \%$ son niñas y el 14\% niños. Las edades más vulnerables están en los 10 años y los 15 años. (Arboleda y González 2017)

La situación se agudiza a partir del 2013. No se trata de señalar que allí empieza el problema, pues estamos ante un tipo de violencia que rebasa los tiempos, los estratos económicos, los terrenos culturales; se articula al patriarcalismo como forma civilizatoria. Las noticias de delitos sexuales pasan de 74 en 2013, a 132 en 2014, 202 en 2015, 229 en 2016 
(Arboleda y González 2017), y se convierte en viral en 2017, coincidiendo con el paso al nuevo gobierno y la oportunidad de hablar.

En el 2016, 1649 agresiones se registraron por los Distritos Educativos en las instituciones públicas: 378 delitos sexuales, 404 violencia física y 867 maltrato sicológico (Arboleda y González 2017). Desde 2008 a octubre de 2017, el Ministerio de educación contabilizó 919 denuncias de violencia sexual, un promedio de 102 casos por año; el 51\% fueron cometidos por docentes y están involucrados compañeros, conserjes y hasta choferes de los buses escolares. (Unidad de Investigación 2017). En 2017, según la Fiscalía, había 4.500 denuncias de abusos a menores, de los cuales 717 corresponden al sistema educativo. Al final del año el número de denuncias llegó a 884, aunque organismos de defensa de los derechos de los niños y niñas señalan que muchos casos se callan.

\section{Los nombres}

En cada caso, el horror y el dolor. Veamos tres casos que pueden mostrar el alcance de la violencia absoluta desde diversos ángulos; no para la "compasión” (Bustelo 2007) que evoca a la víctima desde la debilidad, bajo una mirada paternalista-maternalista, y arrebata el alma del niño/a concreto/a; sino para tomarlos como puntos de referencia a fin de ver la raíz y el alcance la violencia, la guerra contra los niños y niñas, su relación con el poder - el biopoder - y el negocio capitalista.

\section{Caso 1: AAMPETRA}

El aula de Sexto C se volvió oscura. El profesor José Luis Negrete Arias insistió en tapar las ventanas. Los padres de los 41 estudiantes compraron las cortinas para proteger a sus hijos del sol, sin saber que el peligro estaba adentro. Allí, durante once meses, el docente sin título universitario insultó, torturó y abusó sexualmente de todos los alumnos sin que nadie lo notara.

Negrete calculó el horror de cada día. Al cerrar la puerta del salón, el profesor obligaba al grupo a enfrentarse a golpes o con pistolas de balines. Dos niños vigilaban siempre por una rendija. Negrete forzaba a quienes asistían a sus clases a repetir escenas de las películas pornográficas que mostraba. Con sus manos gruesas desnudaba a las niñas, las tocaba y rayaba con un marcador sus partes íntimas. En esa aula, Negrete violó al menos a una de ellas. 
Si los estudiantes se rehusaban a seguir sus órdenes eran azotados con un cable, castigados con un palo o quemados con un mechero en zonas poco visibles de sus cuerpos. Tenían entre 10 y 11 años. Y estaban seguros de que ese hombre de mirada perversa, que fingía hablar con sicarios durante las horas de clase, cumpliría la amenaza de matar a los padres e incendiar la casa del primero que hablara. Él sabía dónde vivían y les llamaba por teléfono si faltaban a clases.

Una de las estudiantes que testificó en el juicio, recuerda el salón como "una cárcel chiquita”. Durante el año lectivo 2010-2011, en medio de uno de los colegios más grandes del sur de la ciudad, los niños y niñas quedaron atrapados por la violencia de su profesor.

Éste es el relato descarnado realizado por Cristina Arboleda e Isabel González (La herida oculta 2017) sobre la violencia sexual contra 41 niños, en la Academia Aeronáutica Pedro Traversari (AAMPETRA), una institución educativa privada ubicada en el Sur de Quito. No se trata de un caso aislado; es un caso que muestra la nueva violencia. El profesor actúa con plena conciencia, un signo de la racionalidad cínica que impera en el sistema patriarcalista decadente, actúa con conocimiento, a pesar del conocimiento; el escudo iluminista de la modernidad es incompetente para contener las nuevas formas de violencia contra la vida. Las promesas incumplidas de la modernidad sobre el humanismo se permutan en formas extremas de deshumanización. El profesor construye la celda con el aporte de los padres de familia. Ejerce la violencia cada día, durante todo un año lectivo 2010-2011 contra 41 alumnos. Crea un ambiente de terror permanente, el cuarto obscuro que luego se extiende al dormitorio de los niños, al bus público, a las calles.

La frontera entre lo público y lo privado desaparece; aún más el espacio privado, íntimo, de la escuela es el terreno de la violación, de la muerte. No se trata únicamente de la escuela-cárcel-panóptico de Foucault, sino el campo de concentración de Agamben, más allá del homo sacer y la nuda vida de los que se quedan sin voz ante el terror cotidiano del riesgo de la muerte, ahora se constituye un nuevo espacio de la violencia absoluta, puer-sacer, la nuda vida de los in-fans, sin voz.

Y el dolor no se agota allí, en el acto individual del agresor, sino que se prolonga en la actitud del establecimiento, la resistencia del Rector-gerente-propietario de la Academia para cumplir la medida simbólica de resarcimiento con el develamiento de una placa, "En memoria de las víctimas de abuso infantil en el sistema educativo.” Interpuso diversos recursos para no 
cumplir la disposición judicial, bajo el argumento de proteger el ¡buen nombre! de la institución.

La ironía o cinismo empieza en el lema y los objetivos de la Academia: "Somos apasionados de la enseñanza y valores de nuestros estudiantes. Coraje, seguridad e integridad. (...) Ofrecemos un ambiente seguro con experiencias de aprendizaje estructuradas donde los alumnos indagan y construyen su propio aprendizaje. Nuestros niños crecen de forma independiente y disfrutan aprender día con día." (AAMPETRA 2017) La raíz está en el giro mercantil y utilitarista de la educación.

No es una actitud excepcional dentro del sistema educativo. La Comisión Parlamentaria AAMPETRA conformada tardíamente sobre estos casos, en su Informe inicial señala que ni siquiera hay un acuerdo entre las autoridades sobre el número de casos: "Según la Fiscalía, en seis años (2012-2017) hubo 1057 denuncias. Sin embargo, la Judicatura maneja una cifra superior (4 864), en tan solo los últimos tres años. De esas, 2264 fueron judicializadas. A nivel del Ministerio de Educación, las denuncias de agresiones en contra de menores sumaron 882, entre 2014 y 2017.” De los 1.057 casos registrados en la Fiscalía entre 2012 y 2017, apenas el 9\% han tenido sentencia, el 27\% han sido archivados, $41 \%$ están en investigación previa, 6\% en instrucción fiscal y 9\% en juicio. (El Comercio 2017)

La Comisión señala que en 30 casos analizados, con más de 420 víctimas, se constata negligencia por parte de las autoridades educativas. En Chimborazo, "el agresor violó a diez niñas en dos centros educativos y en ambos casos la solución fue cambiarlo de plantel." "En el caso de un centro educativo de Santo Domingo, un profesor abusó sexualmente de 14 niñas, maltrató física y psicológicamente a 18 más. El Distrito conoció el hecho y el docente fue destituido, pero no se notificó a la Fiscalía para seguir el proceso penal. El rector no colaboró." En un centro educativo del norte de Quito, en Calderón, la agresión fue contra 84 niños y niñas; el docente agresor fue trasladado dentro del Distrito, para cumplir actividades administrativas, y el Ministerio intervino al centro. (El Comercio 2017)

Hay un sistema de silenciamiento por parte de las autoridades educativas, desde los rectores hasta los ministros. En 2015, de las 264 denuncias de delitos sexuales, apenas 24 (9\%) fueron presentadas por autoridades educativas. Una violencia institucionalizada: el otro cuerpo, "el espíritu de cuerpo" entre los adultos cercanos. Por un momento la conciencia pública se sorprende, pero luego regresa el silencio. Cuando se planteó el enjuiciamiento político al Ministro de Educación por estos casos, la mayoría parlamentaria, controlada por el gobierno, negó el pedido. 


\section{Caso 2: El principito}

El 10 de noviembre de 2014 se registró la denuncia: el "Principito", Lucas, un niño de 5 años, junto a un compañero, fue llevado por el profesor de natación al baño, José Valdivieso Larco, que le ordenó poner los genitales en la boca del amigo, mientras él mostraba su miembro viril. El niño dice que cuando estaba desnudo en el baño, el profesor le daba cachetadas en las nalgas. El agresor fue condenado a 22 años de cárcel, a pesar de que contó con el apoyo de las autoridades del plantel, La Condamine e incluso de algunas figuras vinculadas al Gobierno. Se trata de una institución privada, con aval internacional de Francia, que atiende a niños y niñas, de sectores altos y medios de Quito.

La confirmación del niño a través de diversos medios, trató de ser negada. El caso se complicó por la intervención del poder: la esposa del Presidente de la República, Anne Malherbe, quien era profesora del Colegio, se movilizó, en una de las pocas apariciones en público, en favor del acusado; y aparece como abogado defensor Caupolicán Ochoa, abogado de Rafael Correa en múltiples casos.

El agresor apeló la sentencia, evadió los controles y fugó, después de no haber cumplido por meses la medida cautelar sustitutiva de presentarse cada lunes en los Tribunales Penales de Pichincha, concedida por el Tribunal por encima de la ley, pues en este tipo de delitos no aplica la sustitución de la prisión preventiva, ya que, según el Código Integral Penal, “prima el interés del menor". La Corte Provincial de Pichincha ratificó la sentencia de 22 años y, cuatro años después del delito, la Corte Nacional de Justicia inadmitió el recurso de casación que presentó el acusado. (Ortiz 2018)

Las instituciones educativas, públicas y privadas, no han dado los pasos necesarios para prevenir y actuar ante estos casos. En el caso del "Principito", se repite el patrón de espíritu de cuerpo de la Institución educativa y de no aceptación de la palabra de la víctima. Quizás también hay un elemento de incredulidad, pues a menudo los agresores se presentan como personas "normales" en su vida cotidiana; lo que genera comportamientos de naturalización de las agresiones en el entorno. La invasión del campo íntimo de los niños y niñas por sus "protectores", muestra el carácter absoluto de la violencia.

Caso 3: Redes 
El viernes 15 de diciembre de 2017, desapareció en Loja la niña Emilia Benavides Cuenca, de 10 años de edad. "A los tres años y once meses la incertidumbre vuelve a rondar las calles de Loja (...) que evoca el extravío de María del Cisne Conde Guamán, cuando ella frisaba los 7 años de edad." (La Hora 2017) Hasta el momento no hay datos del paradero de María del Cisne. ${ }^{3}$

Emilia desapareció desde las 12:42 horas del viernes 15, a tres cuadras del plantel educativo privado, donde cursaba el sexto de básica. La ciudad se movilizó para buscar a la niña. El Estado movilizó a la policía, los bomberos, los militares para la búsqueda.

Emilia solía tomar el bus para llegar a la escuela y retornar al hogar. En una cámara de video-vigilancia se observó a Emilia esperando el bus, y que un desconocido se acercó a la menor. El martes 19, la policía detuvo al sospechoso, José Fabián Nero Robalino, Instructor de baile del Programa Ejercítate Ecuador, un amigo de los padres de la niña, Ángel Vinicio Benavides y Olga Cuenca. El detenido confesó el delito e informó sobre el caso. Secuestró a la niña y la llevó a uno de los moteles de Loja, para tomar las fotografías de pornografía infantil; estuvo acompañado por Tania R. A. Con las declaraciones, se pudo ubicar el cuerpo de la niña en el fondo de una quebrada, en la carretera Loja-Catamayo, a cuatrocientos metros de la Parroquia Cuchiquiribamba. El cuerpo había sido incinerado y mutilado.

Después del hallazgo del cuerpo, el padre dijo que él no busca venganza en contra del presunto autor de la muerte de su hija. "Dejo en manos de Dios y de la justicia su juzgamiento." No se puede cobrar vida por vida, pues no se debe comparar la vida de Emilia con la vida de un asesino. Este gesto, si bien personal y desde una visión religiiosa, hay que valorarlo como un intento de escapar a la lógica punitivista impulsada por los mass media. "El poder distorsivo del discurso mediático organizado por el biopoder represor es tan fuerte como para constituir a un padre dolorosamente herido por la muerte de su hijo en el titular reclamante de la prisión, de las condenas más severas y hasta del trabajo forzado para los hijos e hijas de otros padres de un origen socioeconómico distinto.” (Bustelo 2007, 102)

En un escalonamiento sobre la naturaleza del caso, se detuvo a dos cómplices, Manuel Ambuludi Robalino, en cuyo taxi se habría trasladado el cuerpo de la niña hasta la quebrada en que fue arrojado, y Tania R. A., integrantes de una red de pornografía infantil y de trata de niños, niñas. Trasladados desde el Centro de Detención de Loja al Centro de Detención de

\footnotetext{
${ }^{3}$ El dolor de los padres es más desolador cuando el cuerpo del niño violentado no aparece. Al dolor de la violencia se añade el dolor dela ausencia, de la incertidumbre. El grito, devuélvanme al menos el cuerpo de mi niño, de mi niña, expresa la angustia extrema, la zozobra sin consuelo. Eso explica la persistencia de las búsquedas incansables de los padres de los Hermanos Restrepo, de la madre de David Romo.
} 
Turi en Cuenca, el primer implicado apareció ahorcado a las 7:15 horas. Queda la sospecha del asesinato, para silenciar a un delator.

No se trata de un caso privado de un crimen sexual; hay una conexión de redes de trata de personas y de pornografía infantil (La Hora 2017). Las redes se conectan con los grandes poderes y con los grandes negocios. "El primer dispositivo biopolítico es el poder directo sobre la vida como negación de la vida o la política de expansión de la muerte." (Bustelo 2007, 18)

\section{Puer sacer}

Ese campo de conexión extrema entre la nuda vida del niño y la violencia en el campo íntimo de la familia, la escuela y la iglesia, con las nuevas formas de mercantilización del cuerpo, la prostitución infantil, la pornografía infantil amplificada por los medios virtuales, el comercio de órganos, bajo el control de mafias transnacionales, muestra el dominio absoluto del biopoder en el estadio de partida de la vida. Las sombras del puer sacer caminan como fantasmas, almas en pena sin la responsabilidad ni del Estado ni de la sociedad: los pequeños cuerpos de las niñas y niños migrantes sobre la arena, de las niñas y niños destrozados por los bombardeos, los números de niñas y niños náufragos, caídos en la fuga de la guerra, de la muerte, las estadísticas de niñas y niños desaparecidos, sin cuerpo.

Entramos en el campo de la biopolítica, del ser de las personas. "La biopolítica tiene que ver tanto con la regulación de los cuerpos y de la vida como con la construcción de la subjetividad. (...) La forma paroxística del homo sacer de Agamben es el niño sacer pues en él se muestra, por antonomasia, la clausura de la vida, y nadie se hace responsable por ello. El niño sacer reúne esa cruel condición en la que todos condenan su muerte pero, simultáneamente, ésta queda siempre impune.” (Bustelo 2007, 11 y 12)

Las respuestas se han movido en el campo jurídico. "El 20 de noviembre de 1989 la Asamblea General de las Naciones Unidas, de forma unánime aprobó la Convención sobre los Derechos del Niño, entró en vigencia el 20 de septiembre de 1990, una vez que 20 Estados ratificaron este instrumento jurídico internacional. La Convención planteó un nuevo paradigma en relación con los niños, niñas y adolescentes al reconocerles como sujetos plenos de derechos, lo que implicó un cambio en su situación jurídica, social y política." (Calero 2017).

Se pasa de la Doctrina de la situación irregular, el Estado atiende a los niños que están en situaciones que afectan sus derechos (pobreza, trabajo infantil, falta de acceso a la 
educación), con programas de asistencia social, reeducación, etc.; mientras los niños en situación "regular" son una cuestión privada de la familia; a la Doctrina de la protección integral que plantea "la responsabilidad de los Estados de respetar, proteger y garantizar los “derechos humanos y específicos” de los niños, niñas y adolescentes.” (Calero 2017)

Pero este mismo paso en el texto original de la Convención se realiza en forma ambigua. "Es importante aclarar, desde el inicio, que la CIDN, en su artículo 3 inciso 1, habla del "mejor interés del niño" (the best interest of the child) y no del interés "superior" del niño. En la versión original, la propuesta consistía en ese interés "superior" del niño (the paramount interest) pero varios países se opusieron, y la versión final estableció definitivamente "el mejor" interés del niño. Este cambio fenomenal introdujo un relativismo insuperable que trasunta un espíritu paternalista, pues: ¿quién define ahora qué es "lo mejor" para los niños?" (...) Más confusión añade el artículo 21, que establece que hay que darle a este principio la consideración "primordial" en los sistemas de adopción. "Importante", "principal", "primordial" son términos que están referidos a situaciones en donde debe definirse explícitamente el contexto de su aplicación.” (Bustelo 2007, 81 y 82)

Las luchas de los defensores de los niños, de las madres, el sufrimiento y la presencia de los niños y niñas en el mundo, han permitido avances también en el campo normativo. La Observación General 14 del Comité de Derechos del Niño, sobre el Interés Superior, interpreta este "mejor interés" como el "interés superior", define la responsabilidad que implica este "interés superior" desde la mirada del sujeto de derechos, y lo comprende como "un derecho" de niños, niñas y adolescentes a que su "interés superior" sea una "consideración primordial”. (Naciones Unidas. Comité de Derechos del Niño 2013)

El Ecuador se mueve al ritmo de las normativas y los paradigmas internacionales. "En 1998, el Ecuador introduce en la Constitución el reconocimiento a los derechos de los niños, niñas y adolescentes y los elementos de la Doctrina de la Protección Integral, al tiempo que establece una institucionalidad especializada organizada en el Sistema Nacional Descentralizado de Protección Integral a la Niñez y Adolescencia. Estos elementos se desarrollan en el entonces Código de la Niñez y Adolescencia y, en su mayoría se mantienen en la Constitución de la República aprobada en 2008” (Calero 2017). Un paso es el reconocimiento del principio del interés superior, es decir que los derechos de los niños, niñas y adolescentes prevalecen sobre los de las demás personas: "se atenderá al principio de su interés superior y sus derechos prevalecerán sobre los de las demás personas." (Asamblea Nacional 2008, Art. 44). 
Conforme se pasa de la norma constitucional a la ley específica la distancia entre la parte dogmática de proclamación de principios y la parte orgánica de políticas y ejecución, se amplía. Los diversos esfuerzos en este plano entran en contradicción con los hechos: "la situación de niños, niñas y adolescentes en Ecuador se agrava ante la mirada indiferente del Estado y la sociedad. La violencia sexual es una realidad que casi se ha vuelto parte del 'paisaje cotidiano'.” (Calero 2017) “... los derechos se reconocen en su condición de existencia pero se desconocen en su condición de ejercido.” (Bustelo 2007, 88) Allí está el secreto: la declaración abstracta del principio y luego la negación o relativización del derecho concreto. "Cada artículo de la Constitución contiene, en efecto, su propia antítesis (...) En la frase general, la libertad; en el comentario adicional, la anulación de la libertad. Por tanto, mientras se respetase el nombre de la libertad y sólo se impidiese su aplicación real y efectiva -por la vía legal se entiende-, la existencia constitucional de la libertad permanecía integra, intacta, por mucho que se asesinase su existencia común y corriente." (Marx 1981 $(1852))$

Allí se asienta la conciencia de la sociedad y el límite, la distancia entre las palabras y las cosas, entre las normas y los actos. El discurso abstracto, general, sobre los "derechos humanos y específicos de los niños y las niñas", separado de las condiciones concretas del poder y del dominio, fracturado de la posibilidad de mirar la infancia como espacio de liberación integral, termina por mostrar su debilidad para enfrentar un problema que tiene raíces complejas. Mientras se avanza en la precisión de las palabras, crece la indiferencia en las acciones. Se abre un juego de inclusión-exclusión.

Los discursos jurídicos funcionan como dispositivos de desplazamiento-encubrimiento de las relaciones de poder en el tema de la infancia y la adolescencia; con la ley puede tranquilizarse a la opinión pública, anunciar que se actúa desde el Estado y desde la sociedad contra el mal. Las iniciativas de reformas legales centran la mirada en la reforma del Estado, la creación de instituciones públicas de protección y control, la aplicación de normas punitivas que judicializan los casos de violencia infantil, mientras disuelven el objeto específico de los derechos de los niños, niñas y adolescentes, la construcción de su subjetividad, el reconocimiento de formas de vida propias de esta fase, el derecho al "recreo de la infancia", como denomina Bustelo (2007). La cuestión de los derechos de los niños, niñas y adolescentes, se disuelve en temas generales como los derechos de género o los derechos de ciudadanía: “... desde la entrada en vigencia de la nueva Constitución, el Código Orgánico de la Niñez y Adolescencia ha sufrido innumerables cambios -y se enfrenta a otros 
que están en "carpeta”, en los cuales no son los derechos de la niñez y adolescencia el hilo conductor, sino la reforma institucional del Estado, la universalización de los procesos judiciales, la intergeneracionalidad, el ciclo de vida." (Calero 2017)

La tranquilidad de la conciencia social y el formateo de los niños: “... se puede afirmar que el poder ejercido en este campo, más que una propiedad o un atributo, es una estrategia hegemónica de dominación que está compuesta de tácticas subterfugios, tergiversaciones conceptuales, manipulaciones y dispositivos que tienen dos destinos: por un lado, se aplican como legitimación de enfoques $v$ políticas para quienes están dentro del campo y, por el otro, para lograr en el caso de la infancia sujetos obedientes, sumisos y ordenados.” (Bustelo 2007, 28)

Diversas teorías han creado diferentes metáforas para pensar la sociedad. Marx trazó el edificio social sosteniéndose sobre la infraestructura económica. La tópica de Freud se asienta en los primeros cinco años de vida. Foucault dibujó el panóptico como figura del biopoder. Agambem lo amplió a la figura del campo de concentración. Figuras inconclusas en tiempos de la modernidad líquida. Quizás ahora hay que proyectar la figura de una red virtual, sostenida en el último eslabón débil, la edad primera, la infancia, en donde se concentran todas las energías, hacia arriba y hacia abajo. Del lado de la opresión, los dolores de la sociedad - sistema a la vez capitalista y patriarcalista - que recaen sobre el trabajador y el ciudadano, se trasladan-transfieren, dentro del hogar, de la escuela, de la iglesia, en formas de violencias vicarias, sustitutivas, contra las mujeres, contra los extraños, los raros, los otros, y finalmente contra los niños y las niñas. Del lado de la liberación, allí está el campo de las nuevas relaciones de identidad y de ser-con-el-otro, que es parte del padre y la madre, síntesis, condensación, acumulados de herencias culturales, de inconscientes colectivos, y a la vez proyección de los nuevos tiempos en un presente que se hace aquí y ahora.

"El interés superior del niño no tiene sentido fuera de un ámbito de responsabilidades morales. (...) trabajar por la infancia y con ella significa para los adultos un acto de generosidad máxima pues entraña un trabajar para un tiempo que ya no será nuestro y por un lugar que está más allá de nosotros. Trabajar por la infancia significa precisamente despojarse de todo interés. (...) El interés "superior" del niño y que habla de "los niños" en plural, podría haber significado el reconocimiento político del comienzo de una transferencia de poder a las nuevas generaciones considerando así a la infancia como categoría emancipatoria. Por el contrario, en el caso de la CIDN, el "mejor interés del niño" son los 
adultos ya que, en general, son éstos los que deciden y definen "lo mejor" y lo hacen, por supuesto, desde el poder." (Bustelo 2007, 84)

La vida de las niñas y los niños es un tema olvidado. Periódicamente salta a la primera plana de la crómica roja en los momentos de casos extremos. Y entonces la sociedad trata de expiar la culpa con la compasión, y el Estado promete enfrentar el tema, generalmente con nuevas medidas punitivas contra el individuo culpable, el monstruo que se atrevió a violar las normas de la decencia. La violencia silenciosa, cotidiana, dentro del hogar, la escuela, la iglesia, sigue siendo un asunto privado, normalizado, naturalizado, bajo la discrecionalidad de los adultos. La violencia infantil en los mass media y en las redes sociales es parte del formateo permanente de los individuos para bloquear las posibilidades de una conciencia crítica y el reconocimiento de que en la edad primera se define las bases de la liberación y de la identidad.

"Millones de niños y niñas mueren en silencio impunemente o sobreviven en la zoé. Es de no creer que la mayoría de la intelectualidad occidental coloque este problema en el ámbito de la compasión y su solución como un tema de asistencia humanitaria. Afirmo que éste es "el" problema más sustantivo en el campo de los derechos humanos puesto que, al igual que las experiencias de la Shoah y del Gulag, su acontecer es sistemáticamente ocultado y el laissez passer político que se practica puede ser asimilado a las formas más brutales de la biopolítica. Por eso se necesita una inteligencia de la indignación que abra un espacio para que la práctica de los derechos humanos pase cada vez más a concebirse como lucha política por un cambio social, lo que indefectiblemente debe hacer remitir esa práctica al inicio de la vida, esto es, a los derechos de niños, niñas y adolescentes." (Bustelo 2007, 97)

\section{Nosotros}

La agonía se concentra en la pregunta: ¿hay salida? Pareciera que en la modernidad líquida todo llega a su forma extrema, la acumulación por desposesión, la violencia absoluta, la racionalidad cínica. El Ángel de la Historia regresa su mirada horrorizada del huracán del pasado y encuentra, al frente, sólo nubarrones. Pero no se trata de la fortaleza del sistema capitalista-patriarcal, sino de su decadencia, de los signos de una crisis sistémica, de la transición de época. Aunque el desenlace no está asegurado, pues estamos ante la disyuntiva de la transformación o la barbarie. 
Quizás el camino es devolver a los niños y niñas el derecho al recreo, al juego, a la risa, a la vida autónoma; volver a creer en el poder de la magia, ver que el poder de Voldemort es derrotado por un niño: "Dicen que quiso matar al hijo de los Potter, a Harry. Pero no pudo. No pudo matar a ese niño. Nadie sabe por qué, ni cómo, pero dicen que como no pudo matarlo, el poder de Voldemort se rompió... y que ésa es la razón por la que se ha ido." (Rowling 1999, 9) Aunque Harry recién descubriría en el año 11 su poder, pues los muggles se oponen y quieren extirpar todo vestigio de la magia. "-Un muggle - respondió Hagrid- es como llamamos a la gente «nomágica» como ellos. Y tuviste la mala suerte de crecer en una familia de los más grandes muggles que haya visto.” (Rowling 1999, 36)

El secreto está en ver cómo actúa el poder para desmontarlo, volver a colocar el bien y el mal como soporte de la vida en común. Enfrentar la racionalidad cínica que se ha convertido en la norma de la modernidad líquida. "Lord Voldemort me demostró lo equivocado que estaba. No hay ni mal ni bien, sólo hay poder y personas demasiado débiles para buscarlo...” (Rowling 1999, 202)

Hemos sido formateados en la democracia de los modernos a la consecución de los derechos negativos, lo que no hay que hacer, la defensa de los derechos individuales ante los otros y el Estado. El objetivo de las grandes declaraciones de los derechos humanos, empezando por la Convención de las Naciones Unidas, no es la defensa de la vida de los seres humanos, sino la garantía del orden. no lo que es bueno, sino apenas lo que es correcto. Son los derechos al no-Mal: "No ser ofendido ni maltratado ni en su vida (horror a la muerte y la ejecución), ni en su cuerpo (horror a la tortura, al mal trato y al hambre) ni en su identidad cultural (horror a la humillación de las mujeres, de las minorías, etc.)". (Badiou 1995, 103, citado en Bustelo 2007, 93)

Como dice Sibila, Foucault nos convoca "[...] a considerar la vida como un objeto político, que exige estudiarla en las luchas históricas de las diversas sociedades buscando detectar aquellos instantes preciosos en que ella, inexplicablemente en su voluntad, se revela contra las fuerzas que buscan sujetarla, enriqueciendo las subjetividades y ampliando el campo de lo que existe." (Sibila 2005, 269, citado en Bustelo 2007)

El primer paso es colocar en la agenda de la democracia el tema de la vida de las niñas y los niños, no sólo como un tema de derechos humanos, un capítulo más dentro de las Constituciones o una Ley específica, sino como proceso vital, como fundamento de la vida de la sociedad. Volver a ver a la niña, al niño, como sujetos dentro de la comunidad familiar, escolar, religiosa, humana. "La biopolítica se legitima desligándose de todo lazo social, de 
toda ley común, condenando a la mayoría de las personas a una economía restringida a mera conservatio vitae." (Bustelo 2007, 94) El camino de retorno, ligar la vida del individuo como sujeto de las comunidades, ligar los derechos humanos a los temas de la riqueza y el poder, ligar los derechos negativos a los derechos por una vida digna, puede señalar la puerta de salida.

“Como afirma Bauman (2004, 99 y 107), la responsabilidad hacia los niños y niñas puede ser pensada como la ética de una caricia: "la mano que acaricia siempre se mantiene abierta, nunca se cierra para asir", jamás demanda posesión. Y éste es el sentido más profundo de lo que llamamos "derechos". (Bustelo 2007, 101)

Nos encontramos con los fundamentos y los alcances de la ética. Los derechos de las niñas y los niños para su realización, implican una ética de la "eleidad", el reconocimiento de "ellos" como otros, como sujetos, una ética de la "gratuidad", entregar, dar, sin esperar recompensa. En la visión de Levinas: "El "otro" en su dimensión de alteridad absoluta exige una ética de responsabilidad infinita. (...) La experiencia humana se da por la posibilidad del ser humano de "ser para otro" en una relación ética que implica el cuestionamiento absoluto del yo." (Bustelo 2007, 102)

Ante la violencia absoluta, la ética absoluta: "La crítica no reduce lo Otro al Mismo como la ontología, sino que cuestiona el ejercicio del Mismo. Un cuestionamiento del Mismo - que no puede hacerse en la espontaneidad egoísta del Mismo- se efectúa por el Otro. A este cuestionamiento de mi espontaneidad por la presencia del Otro, se llama ética." (Levinas 2002)

Allí surge el aporte de la otra visión, desde los pueblos originarios de nuestra América, el sentido de la comunidad como ser-con-nos-otros. Aunque en el camino, a menudo, los mismos pueblos indígenas hayan olvidado su raíz, y muestren huellas dolorosas de la violencia infantil. No una renuncia al yo, sino la creación de un nuevo campo compartido, un nos-otros.

El biopoder no planea en el aire. La base material está en la expropiación de la vida del trabajador por el capital, para producir un valor que le es extraño. La clave de las políticas modernas sobre la infancia está en el relevo generacional para la reproducción ampliada del capital en la reproducción de sus actores, no sólo como fuerza de trabajo, sino como trabajadores 'libres' deseantes. La base material en el capitalismo tardío, es el paso a la subsunción real del consumo al capital. "La estructura material de los valores de uso ha quedado determinada de tal manera que responde a las necesidades de la explotación y 
acumulación de plusvalor. En consecuencia, el sometimiento de los seres humanos ya no es sólo económico y político, ni solamente ideológico y cultural, sino también fisiológico; ahora el modo de producción capitalista moldea nuestro modo de vida y el sometimiento político es también psicosocial y, por tanto, sexual.” (Veraza 2008) El capital y el Estado moderno han colonizado todos los espacios de vida en aras de la lógica de la acumulación y la ganancia.

El biopoder se coloca más allá de la norma, se trata de controlar-formatear al individuo en un doble proceso, la creación del trabajador libre: "el futuro creador de la riqueza nada tiene; o sólo tiene ¿una objetividad que de ningún modo es exterior a la existencia inmediata del individuo mismo' (Marx 1976, 235); es un pobre desnudo; es la 'nada' o negatividad anterior, fruto del abandono de la 'comunidad rural' e ingreso a la relación 'social' urbana." Y luego la subsunción formal y real al capital, para una expropiación pacífica, deseada, como única posibilidad de subsistencia. (Dussel 1998, 321322) Un juego de violencia estructural y seducción, sobre todo en tiempos de la modernidad líquida, en donde el poder ya no necesita acudir a su forma represiva abierta, sino que puede operar desde la segurización del poder y del Estado, en una cadena control-temor-deseo.

Desde esta perspectiva el tema de la infancia es la raíz de la reproducción del sistema del capital, no sólo como modo de producción, sino como modo de vida-muerte, como un modo civilizatorio que lleva el dominio patriarcalista a sus formas más depuradas. La defensa de los derechos y la vida de las niñas y niñas entra en una dimensión civilizatoria, postcapitalista y post-patriarcalista.

La infancia más que un paso es un inicio de la vida, otro comienzo de una vida dentro de la comunidad. El infante humano necesita por más tiempo que cualquier otra especie el acompañamiento del adulto. El infante es el que no tiene voz y entra en el lenguaje como forma de construir su identidad. No es un acto individual, sino relacional: el infante se encuentra con los padres, con los maestros, con los jueces, con los pastores, con los comunicadores. Las formas de esta relación pueden trazar infancias plenas o truncas. Hay una pedagogía permanente en esta relación: allí está la condición para edificar la infancia como el tiempo de la cimentación de una identidad autónoma en medio de las presiones de la sociedad. Por tanto, hay un doble comienzo, el del infante y de los padres, maestros, comunicadores, pastores. Hay diversas propuestas para esta pedagogía: paidós-niño/ageinguiar. La clave es centrar el sujeto de la relación en el niño, en el aprendizaje y no en la enseñanza. En nuestra América tenemos un camino abierto en la pedagogía de la 
liberación, la pedagogía de la indignación de Paulo Freire, no sólo para la escuela, sino para las diversas relaciones de entrada en el lenguaje, en la construcción de sujetos, de identidades:

\begin{abstract}
"La transformación del mundo necesita tanto del sueño como la indispensable autenticidad de este depende de la lealtad de quien sueña las condiciones históricas, materiales, según el desarrollo tecnológico y científico del contexto del soñador. Los sueños son proyectos por los cuales se lucha. (...) la transformación del mundo a la que aspira el sueño es un acto político y sería una ingenuidad no reconocer que los sueños tienen sus contra-sueños. El momento del que cada generación forma parte, en tanto momento histórico, revela señales antiguas que involucran comprensiones de la realidad, intereses de grupos, de clases, preconceptos, y gestaciones de ideologías que vienen perpetuándose en contradicción con aspectos más modernos. Por eso mismo, no existe un hoy sin "presencias", que perduran desde hace mucho, en el clima cultural que caracteriza la actualidad concreta. De ahí la naturaleza contradictoria y procesal de toda realidad...". (Freire 2001)
\end{abstract}

Eduardo Bustelo, siguiendo a Michel Foucault, define la actitud del adulto-guía como parrhesía: "Parrhesía etimológicamente significa decirlo todo. La parrhesía lo dice todo; no obstante, no significa exactamente decirlo todo, sino más bien la franqueza, la libertad, la apertura que hacen que se diga lo que hay que decir, cómo se quiere decir, cuándo se quiere decir y bajo la forma que se considere necesaria." (Foucault, La hermenéutica del sujeto 2001, 88, citado en Bustelo 2007, 121)

\footnotetext{
"En la parrhesía hay generosidad, y el locutor no pretende influir en quien escucha; es una actitud diferente del que practica la retórica ya que éste pretende persuadir. Y lo que es más importante: en la parrhesía es preciso que quien habla sostenga su palabra con el testimonio de su vida y de su forma de vida. No hay aquí posibilidad de un doble discurso, lo que es fundamental con la infancia." (Bustelo 2007, 121). "En la parrhesía, el que habla usa su libertad y elige la franqueza en vez de la persuasión, la verdad en vez de la falsedad o el silencio, el riesgo de muerte en vez de la vida y la seguridad, la crítica en vez de la lisonja, y la obligación moral en vez del propio interés y la apatía moral.” (Foucault 2003, 271, citado en Bustelo 2007, 122)
}

La condición es volver al punto de partida. "Todos los mayores han sido primero niños. (Pero pocos lo recuerdan)" (De Saint-Exupéry 2003) Sentir otra vez la magia de la vida, para poder compartirla.

\title{
7. Bibliografía
}

AAMPETRA. «Quiénes somos. Objetivos.» 2017. http://www.aampetra.edu.ec/index.php/programas-academicos.

Agamben, Giorgio. Homo saccer. I. El poder soberano y la nuda vida. España: Pre-textos, 1998. 
Arboleda, Cristina, y Isabel González. La herida oculta. Mayo de 2017. http://sentimosdiverso.org/ee/violenciasexual/ (último acceso: 2 de Febrero de 2018).

Asamblea Nacional. Constitución Política de la República del Ecuador. Asamblea Nacional, 2008.

Badiou, Alain. «Ensayo sobre la conciencia del mal.» En Batallas Éticas, de Thomas Abraham y otros. Buenos Aires: Nueva Visión, 1995.

Bauman, Zygmunt. Ética postmoderna. Buenos Aires: Siglo XXI, 2004.

Bourdieu, Pierra. La dominación masculina. Barcelona: Anagrama, 2000.

Bustelo, Eduardo. El recreo de la infancia. Argumentos para otro comienzo. Primera. Buenos Aires: Siglo XXI Editores Argentina, 2007.

Calero, Patricia. Derechos de los niños: De la declaración formal a la indiferencia. Quito, 7 de Agosto de 2017.

Coalición Nacional de Mujeres del Ecuador. «INFORME ALTERNATIVO Del cumplimiento de la Convención sobre los Derechos del Niño y sus Protocolos Facultativos por parte del Estado Ecuatoriano.» 2016.

Comisión de Transición e INEC. «Encuesta Nacional de Relaciones Familiares y Violencia de Género.» Quito, 2011.

De Saint-Exupéry, Antoine. El Principito. Ecuador, 2003.

De Sepúlveda, Juan. De la justa causa de la guerra contra los indios. Roma, 1550.

Dussel, Enrique. Ética de la liberación en la edad de la globalización y de la exclusión. Trotta, 1998.

El Comercio. «La Comisión Aampetra de la Asamblea revela negligencia en 30 casos de abuso sexual en escuelas.» 22 de Noviembre de 2017.

http://www.elcomercio.com/actualidad/aampetra-negligencia-casos-abusosexualescuelas.html.

Engels, Federico. La situación de la clase obrera en Inglaterra. Archivo Marx-Engels, 1845.

Foucault, Michel. «Coraje y verdad.» En El último Foucault, de Tomás Abraham. Buenos Aires: Sudamericana, 2003.

—. La hermenéutica del sujeto. La Plata: Altamira, 2001.

Freire, Paulo. Pedagogía de la indignación. Cartas pedagógicas en un mundo revuelto. Madrid: Morata, 2001.

La Hora. «Fuente clave en crimen de Emilia se silenció...» La Hora, 22 de Diciembre de 2017.

—. «La supuesta desaparición de Emilia evoca a la perdida de María del Cisne.» La Hora, 19 de Diciembre de 2017.

Lerner, Gerda. La creación del patriarcado. Barcelona: Editorial Crítica, 1990.

Levinas, Emmanuel. Totalidad e infinito. Salamanca: Sígueme, 2002.

Marx, Carlos. «El 18 Brumario de Luis Bonaparte.» En Obras escogidas, de Carlos Marx, 404-498. Moscú: Progreso, 1981 (1852).

-. Elementos fundamentales para la crítica de la economía política (Grundrisse). Vol. I. México: Siglo XXI, 1976.

—. Introducción a la crítica de la Filosofía del Derecho de Hegel. 1956 (1844). 
Naciones Unidas. Comité de Derechos del Niño. «Observación general Nº 14 (2013) sobre el derecho de los niños a que su interés superior sea una consideración primordial (artículo 3, párrafo 1).» 2013.

Nancy, Jean-Luc. La comunidad inoperante. Santiago de Chile: Escuela de Filosofía Universidad ARCIS, 2000.

Ortiz, Sara. «Profesor condenado en el caso Principito evadió control y se fugó.»El Comercio, 11 de Enero de 2018.

Quijano, Aníbal. Colonialidad del poder,eurocentrismo y América Latina. Lima: CIES, 2000. Rowling, J.K. HARRY POTTER Y LA PIEDRA FILOSOFAL . Barcelona: Emecé Editores España, 1999.

Sibila, P. El hombre postorgánico. Cuerpo, subjetividad y tecnologías digitales. Buenos Aires: Fondo de Cultura Económica, 2005.

Unidad de Investigación. «Ecuador: 102 casos de abuso sexual en centros educativos al año.» El Telégrafo, 11 de Diciembre de 2017.

Veraza, Jorge. Subsunción real del consumo al capital. México: Itaca, 2008.

Viteri, María Amelia, y otros. «Patrones de violencia hacia las niñas en el Ecuador.» Editado por Universidad San Francisco de Quito. Revista Bitácora Académica, nº 3 (Junio 2017). 